\title{
A RANDOMIZED CLINICAL ENDPOINT STUDY TO EVALUATE THE SAFETY AND EFFICACY OF CLEARLIV TABLETS IN PATIENTS WITH ALCOHOLIC LIVER DISEASE
}

\author{
RAMESH KANNAN S ${ }^{1}$, SIVARAMAN V ${ }^{1}$, MRINALINI $C^{2}$, SAKTHIBALAN ${ }^{2 *}$, JAYASHREE S $^{2}$, VANANGAMUDI SS ${ }^{3}$, \\ NAGARAJAN KM ${ }^{3}$, ARTHER PAUL $\mathrm{C}^{3}$
}

${ }^{1}$ Department of Pharmacology, Madras Medical College, Chennai, Tamil Nadu, India. ${ }^{2}$ Co-Investigators, KI3 (CRO), Chennai, Tamil Nadu, India. ${ }^{3}$ Co-Investigators, Apex Laboratories Pvt. Ltd., Chennai, Tamil Nadu, India. Email: kai3.mrg@gmail.com.

Received: 24 September 2018, Revised and Accepted: 02 November 2018

ABSTRACT

Objective: The objective of this study was to evaluate and compare the hepatoprotective effect of clearliv tablets with silymarin in patients with alcoholic liver disease.

Methods: This was a prospective, randomized, multicenter, open-label, parallel group interventional clinical endpoint study (Phase IIa). Patients attending general medicine outpatient department were screened for alcoholic liver disease using the serum biochemical liver function test and ultrasonogram abdomen and tested whether they satisfy the selection criteria, and 24 patients were then enrolled in the study. The study drug, namely clearliv tablets of Apex Laboratories Pvt. Ltd., was administered to Group A and tablet silymarin was administered to Group B from day 1 to day 56. Patients were reviewed once in 2 weeks. Liver function test was repeated, and patients were enquired of their well-being and any adverse events.

Results: The demographic characters and body weight of the subjects showed no significant difference between the groups. There is a significant improvement $(\mathrm{p}<0.05)$ in the aspartate transaminase (AST), alanine transaminase (ALT), and total bilirubin (TB) levels on $28^{\text {th }}$ and $56^{\text {th }}$ days in both silymarin and clearliv groups. Of the 2 groups, there is higher significance of improvement in clearliv group $(\mathrm{p}<0.001)$, compared to silymarin group. Clearliv group started showing a significant reduction in AST and ALT levels in the first 14 days of the study period. On comparing the mean percentage reduction in the levels of AST (35.7\% and 35\%), ALT (26.7\% and $24.3 \%)$, and TB (26.7\% and 25\%), it was found that clearliv is showing a better percentage of reduction of the above parameters compared to silymarin. There were reports of adverse effects such as loss of appetite and gastritis in both the groups.

Conclusion: This clinical study proves that clearliv is functioning as a hepatoprotective drug. It is offering a better hepatoprotection compared to silymarin. Clearliv tablets can be indicated for the management of liver dysfunction, which occurs due to alcoholic liver damage. It may also be used in similar manner in cases of viral hepatitis, drug-induced liver damage, acute and chronic hepatitis.

Keywords: Alcoholic liver disease, Hepatoprotective, Clearliv, Silymarin.

(C) 2019 The Authors. Published by Innovare Academic Sciences Pvt Ltd. This is an open access article under the CC BY license (http://creativecommons. org/licenses/by/4. 0/) DOI: http://dx.doi.org/10.22159/ajpcr.2019.v12i1.29921

\section{INTRODUCTION}

In the year 2010, the global burden of alcoholic liver diseases was large and resulted in 493, 000 deaths and 14,544,000 disabilityadjusted life years. This burden represented $0.9 \%$ of all deaths and $0.6 \%$ of all disability-adjusted life years in 2010 [1]. Alcoholic liver disease encompasses a clinical-histologic spectrum including fatty liver, alcoholic hepatitis, and cirrhosis with its complications [2]. The World Health Organization (WHO) estimates that alcohol is now the third highest risk factor for premature mortality, disability, and loss of health worldwide [3]. There is a growing incidence of hepatocellular carcinoma (HCC) worldwide. The annual global incidence of HCC is over 500,000 cases. The highest incidence of HCC is observed in Asia and Africa, associated with the high prevalence of hepatitis in these regions [4]. The hallmark of therapy in alcoholic liver diseases has been abstinence from alcohol and nutritional therapy. Role of steroids has been accepted in the treatment; however, the effectiveness of therapy should be assessed after 1 week of treatment. Pentoxifylline has been equally effective, especially in patients with renal dysfunction or hepatorenal syndrome. The use of biologics has been disappointing in the treatment of alcoholic liver diseases [5].

India is the largest producer of medicinal plants. The medicinal plants have very important role in the health of human beings as well as animals. As per the WHO estimates, about three-quarters of the world's population currently use herbs and other traditional medicines to cure various diseases, including liver disorders [6].

Clearlivis, a research product (ferbal medicine), was developed by Apex Laboratories Ltd., for hepatoprotection. Clearliv has a composition as follows: Ricinus communis: $42.85 \mathrm{mg}$, Phyllanthus niruri: $25 \mathrm{mg}$, Eclipta alba: $15 \mathrm{mg}$, Boerhaavia diffusa: $12.5 \mathrm{mg}$, Tinospora cordifolia: $10 \mathrm{mg}$, Tribulus terrestris: $14.28 \mathrm{mg}$, Tephrosia purpurea: $11.11 \mathrm{mg}$, Indigofera tinctoria: $9.37 \mathrm{mg}$, Andrographis paniculata: $6.25 \mathrm{mg}$, Rubia cordifolia: $5 \mathrm{mg}$, Terminalia chebula: $12.5 \mathrm{mg}$, Curcuma longa: $3.5 \mathrm{mg}$, and Aconitum Heterophyllum: $10 \mathrm{mg}$. The formulation has been validated scientifically and traditional claims have been supported by scientific data. Standardization of all the extracts has been established without losing the essence of the Ayurvedic tradition. In an animal study conducted by Kumar et al., it was shown that clearliv in doses of 800 and $1000 \mathrm{mg} / \mathrm{Kg}$ has a significant hepatoprotective action against various hepatotoxicantinduced liver necrosis and injury [7]. Clearliv tablets are formulated in such a way that it offers three clear benefits in liver care, i.e., clearliv tablets conserves the liver, controls the liver damage and corrects the liver functions. Clearliv tablet is indicated for the management of liver dysfunction which may occur due to alcoholic liver damage, viral hepatitis, drug-induced liver damage, and acute and chronic hepatitis. Clearliv tablet can also be prescribed during pregnancy for intrahepatic cholestasis and associated constipation. 
Herbal medicines have been used in the treatment of liver diseases for a long time; however, standardization of herbal medicines has been a problem. Hence, the rationale behind this study is that we have standardized a herbal medicine for liver disease, and if it is efficacious without any side effects, then it can be useful for the population suffering from liver disease at a cheaper cost compared to the current treatments available. Prospective, randomized, controlled clinical trials are also lacking to support their efficacy [8]. Hence, with an aim to evaluate the efficacy and safety of the clearliv tablets in patients with liver dysfunction, like alcoholic liver disease in comparison with standard drug such as silymarin, the present study was conducted.

\section{METHODS}

This was a prospective, randomized, multicenter, open-label, parallel group interventional clinical endpoint study (Phase IIa). The study was conducted at two centers in India at Mahatma Gandhi College and Hospital, Pondicherry, and PM Medical Centre, Walajapet, Tamil Nadu, according to good clinical practice. The study was initiated after obtaining proper ethical committee approvals in ki3 ethics committee. The study was registered in the Clinical Trial Registry of India (No: CTRI/2018/03/012644), and Drug Control General of India (AYUSH) was notified (Notification No: 2730). Informed written consent was obtained from the patients attending general medicine outpatient department. Then, they underwent general and systemic examination followed by laboratory tests for hematology, blood biochemistry, blood microbiology, urine analysis, electrocardiogram, and chest X-ray for initial evaluation and were screened for alcoholic liver disease using the serum biochemical liver function test and ultrasound sonography abdomen and tested whether they satisfy the selection criteria, and 24 patients were then enrolled in the study.

Patients recruited in the study were belonged to:

a. Either sex and 18-70 years of age, with chronic alcohol intake.

b. Patients in whom serum aspartate transaminase (AST) and alanine transaminase (ALT) were typically elevated to a level of 2-6 times the upper limit of normal, and patients who tested negative for HIV, hepatitis B, and C.

c. Female patients who tested negative for pregnancy (up to 2 weeks before the study) were included in the study.

Patients who were excluded from the study were as follows:

a. Those who had liver disease with the cause different from that of alcohol-induced liver disease.

b. Patients who were suffering from hepatic failure, hepatic cirrhosis, Wilson's disease, malignant tumor, serious metabolic disease, severe renal disease, severe pulmonary disease, severe cardiovascular disease, severe nervous disease/psychiatric disorder, and muscular disorders.

c. Pregnant or lactating women

d. Patients with comorbidities and reduced life expectancy, patients known to be dependent on drugs, and patients with any known hypersensitivity or allergy to any component of the drugs involved in the study.

e. Patients who were on medications that may affect treatment such as colchicine, penicillamine, corticosteroids, ursodeoxycholic acid, pentoxifylline, long-term use of statins, neuroleptics, anti-convulsant medications, and high-dose acetaminophen ( $>2.5 \mathrm{~g} /$ day).

f. Patients who may have participated in recent past (past 3 months) in a clinical trial.

Eligible subjects were randomly selected through computer-generated randomization using simple randomization and were divided into Groups A and B. The study drug, clearliv tablet (2 tablets twice daily postprandial), was administered to Group A and silymarin tablet (70 mg twice daily post prandial) was administered to Group B from day 1 to day 56 at the specified time of the day. The drugs were provided to the patients at each visit (once in 2 weeks) along with a patient diary to monitor the compliance. The patients were reviewed on days $14,28,42$, and 56 . Liver function test was repeated, and the patients were enquired for their well-being, adverse events, and compliance.
Patients were strictly advised not to consume alcohol throughout the study period. Counseling for alcohol abstinence was given at each visit. Further course of the treatment for the test subjects was based on the discretion of the investigator. The reports were compiled. Continuous data were reported using the descriptive statistics using mean and standard deviation. For analyzing continuous data, student's t-test followed by Mann-Whitney U-test and two-way ANOVA was applied. $(p<0.05)$ was considered as statistically significant. All the statistical analyses were performed using SPSS 23.0 software.

\section{RESULTS}

All the 24 patients selected for the study completed the study. There were no dropouts. Complete disposition of the study participants is given in Table 1.

The efficacy of both control and test drugs was found to be similar, and there was no statistically significant difference observed between the two. The efficacy was observed as an improvement in the AST, ALT, and total bilirubin (TB) levels from the baseline as a result of the treatment with the two drugs. Table 2 enumerates the comparison of mean percentage improvement between the control and the test groups (Figs. 1 and 2).

Gastritis and loss of appetite were the two adverse events observed during the study period. None of the patients experienced nausea, vomiting, diarrhea, cardiovascular side effects, or neurological side effects. Among 12 subjects in the treatment group, four subjects reported loss of appetite and five subjects reported symptoms of gastritis which resolved on its own. Among the 12 subjects in the control group, 6 reported a decrease in appetite and 8 subjects reported symptoms of gastritis which resolved on its own. No other serious adverse events were reported during the study period. Table 3 enumerates the adverse events recorded during the study period.

Table 1: Baseline demographic parameters

\begin{tabular}{lll}
\hline Parameter $^{\#}$ & $\begin{array}{l}\text { Silymarin group } \\
\text { (control group) }(\mathbf{n = 1 2})\end{array}$ & $\begin{array}{l}\text { Clearliv (test } \\
\text { group) }(\mathbf{n = 1 2})\end{array}$ \\
\hline Gender, n (\%) male & 100 & 100 \\
Age & $39.08 \pm 7.76$ & $36.3 \pm 4.3$ \\
Body weight & $76.8 \pm 7.87$ & $78.03 \pm 7.04$ \\
AST level (IU) & $141 \pm 19.04$ & $142.58 \pm 22.73$ \\
ALT level (IU) & $68.2 \pm 11.09$ & $69 \pm 12.22$ \\
TB (mg/dl) & $1.8 \pm 0.48$ & $1.87 \pm 0.30$ \\
\hline
\end{tabular}

AST: Aspartate transaminase, ALT: Alanine transaminase, TB: Total bilirubin,

\#: Two-way ANOVA followed by Bonferroni post-test, $\mathrm{p}$ value was not significant for baseline parameters

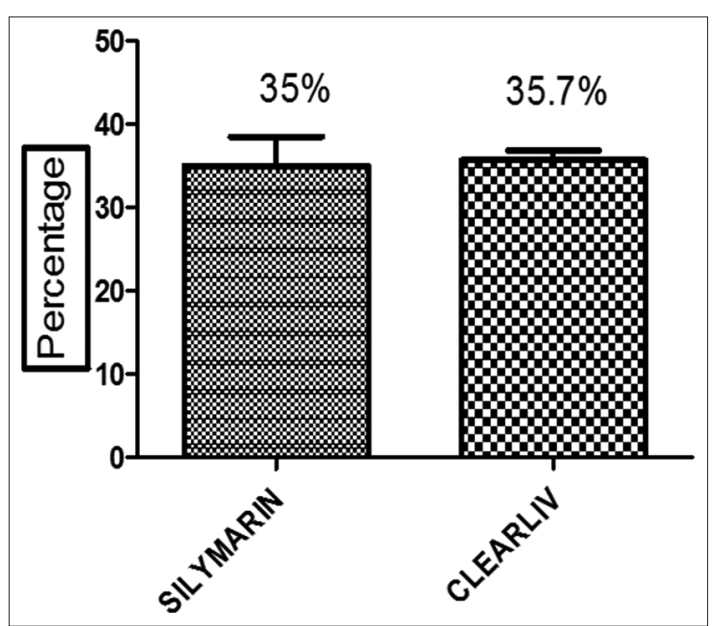

Fig. 1: Comparison of mean percentage reduction in aspartate transaminase levels ( $n=12$ subjects per group) 


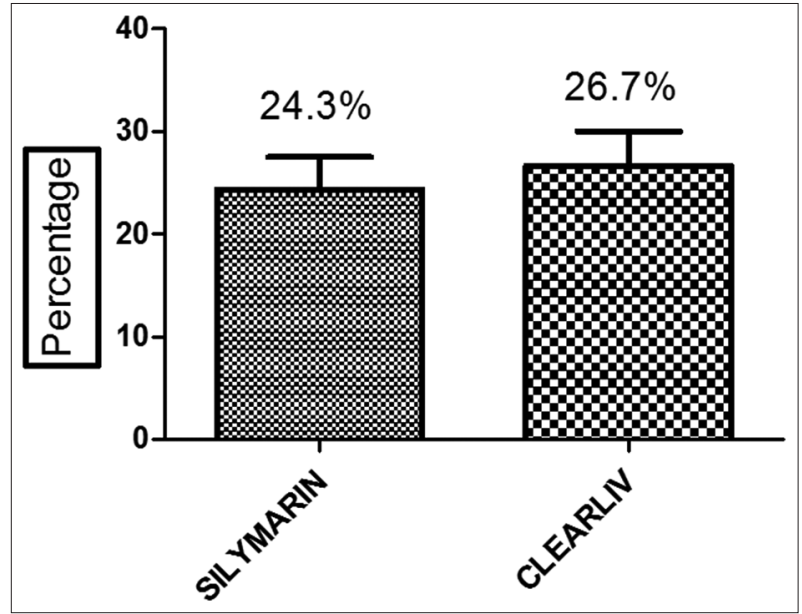

Fig. 2: Comparison of mean percentage reduction in alanine transaminase levels ( $n=12$ subjects per group)

Table 2: Comparison of percentage reduction in AST, ALT, and TB levels at various follow-up visits

\begin{tabular}{lllll}
\hline Parameter $^{\#}$ & \multicolumn{2}{l}{$\begin{array}{l}\text { Mean (\%) } \\
\text { improvement }\end{array}$} & p value & Significance \\
\cline { 2 - 3 } & $\begin{array}{l}\text { Control } \\
\text { group }\end{array}$ & $\begin{array}{l}\text { Test } \\
\text { group }\end{array}$ & & \\
& & & & \\
\hline AST & 28 & 34 & $>0.05$ & NS \\
Day 14 & 28 & 38 & $>0.05$ & NS \\
Day 28 & 39 & 35 & $>0.05$ & NS \\
Day 56 & 38 & & & \\
ALT & & & $>0.05$ & NS \\
Day 14 & 28 & 30 & $>0.05$ & NS \\
Day 28 & 18 & 20 & $>0.05$ & NS \\
Day 56 & 27 & 30 & & \\
TB & & & $>0.05$ & NS \\
Day 14 & 45 & 45 & $>0.05$ & NS \\
Day 28 & 10 & 9 & $>0.05$ & NS \\
Day 56 & 20 & 26 &
\end{tabular}

AST: Aspartate transaminase, ALT: Alanine transaminase, TB: Total bilirubin,

": Two-tailed student t-test followed by Mann-Whitney U-test was performed. $\mathrm{p}<0.05$ is considered statistically significant, NS: Not significant

Table 3: Adverse events occurred during the study period

\begin{tabular}{llll}
\hline S. No & Type of adverse events & $\begin{array}{l}\text { Number of } \\
\text { subjects in } \\
\text { control group } \\
\text { - Silymarin } \\
\text { (n=12) }\end{array}$ & $\begin{array}{l}\text { Number of } \\
\text { subjects in } \\
\text { test group } \\
\text { Clearliv } \\
\text { (n=12) }\end{array}$ \\
\hline 1 & Gastritis & 8 & 4 \\
2 & Nausea & 0 & 0 \\
3 & Vomiting & 0 & 0 \\
4 & Diarrhea & 0 & 0 \\
5 & Loss of appetite & 6 & 5 \\
6 & Cardiovascular side effects & 0 & 0 \\
7 & Neurological side effects & 0 & 0 \\
\hline
\end{tabular}

\section{DISCUSSION}

There was no significant difference between the demographic characteristics of the two groups. None of the patients showed any discomfort in the usage of clearliv. As is observed from the measurement of primary outcome, there is an extremely significant improvement in the AST, ALT, and TB levels on $28^{\text {th }}$ day and $56^{\text {th }}$ day of the treatment, both in the silymarin and clearliv groups. However, it is noticeable that the patients in the clearliv group started showing a significant reduction in AST and ALT levels in the first 14 days of the study period which was not seen the silymarin (control) group. A comparison of the percentage reduction in the levels of AST, ALT, and TB (Table 2) showed that both silymarin and clearliv were equally effective, but clearliv demonstrated a better overall reduction in percentage values of these parameters. There was a remarkable overall improvement in the well-being of the study subjects, both in the test and the control groups. However, the improvement was better in clearliv group.

Thus, clearliv is showing a hepatoprotective action. The main components of clearliv which includes Ricinus communis or castor plant has shown hepatoprotective activity in a previous studies done by Pingale et al., [9] and Visen et al., [10], where the extracts of Ricinus communis leaves was used against hepatosuppression induced by carbon tetrachloride and galactosamine-induced hepatic damage, respectively. The hepatoprotective activity may be due to the important phytochemical constituents such as flavonoids, saponins, glycosides, alkaloids, and steroids in this herb. It was also found out that there were two active intermediate products from the herb, namely ricinine and $\mathrm{N}$-demethyl-ricinine, which were showing hepatoprotective activity.

The other major component, namely Phyllanthus niruri, which originated in India, usually occurring as a winter weed throughout the hotter parts, has been shown to have hepatoprotective properties because of the presence of active phytochemicals, flavonoids, alkaloids, terpenoids, lignans, polyphenols, tannins, coumarins, and saponins. Extracts of this herb have been proven to have therapeutic effects in many clinical studies [11,12]. The hepatoprotective effects of other components, namely Eclipta alba, Andrographis paniculata, Tinospora cordifolia, and Tephrosia purpurea, have been proved in previous studies, by doing biochemical and histopathological assay of liver specimens [13-15].

All the herbs included in clearliv have antioxidant property. The hepatoprotective activity of clearliv is evident from the normalization of AST, ALT, and TB levels. Hence, it can be postulated that the hepatoprotective effect of clearliv tablets is due to the inhibitory effect of the active phytochemicals of each herb, on the free radical formation.

\section{CONCLUSION}

The results of the clinical study have shown that clearliv is an effective hepatoprotective drug offering a comparatively better hepatoprotection as compared to silymarin. A significant reduction in the AST, ALT, and TB levels was observed from $14^{\text {th }}$ day onward in the clearliv-treated group. Both the clearliv and silymarin treatment groups showed a better reduction in the above parameters from baseline at $28^{\text {th }}$ and $56^{\text {th }}$ days of the treatment.

Hence, it can be concluded that clearliv tablets can be indicated for the management of liver dysfunction, which occurs due to alcoholic liver damage. It may also be used effectively in case of viral hepatitis, druginduced liver damage, and acute and chronic hepatitis. We can clearly say that clearliv is not only an effective but also a safe drug to be used in patients with alcoholic liver disease, which may be evaluated further by doing large-scale clinical studies on liver dysfunction caused due to factors other than alcoholic liver disease.

\section{CONFLICTS OF INTEREST}

All authors have none to declare.

\section{AUTHORS' CONTRIBUTIONS}

Ramesh Kannan $\mathrm{S}^{\mathrm{a}}$, Sivaraman $\mathrm{V}^{\mathrm{a}}$, Mrinalini ${ }^{\mathrm{b}}$, Sakthibalan $\mathrm{M}^{\mathrm{b} *}$, Jayashree $\mathrm{S}^{\mathrm{b}}$, Vanangamudi $\mathrm{SS}^{\mathrm{c}}$, Nagarajan $\mathrm{KM}^{\mathrm{c}}$, Arther Paul $\mathrm{C}^{\mathrm{c}}$. a - Principal Investigator, Department of Pharmacology, Madras Medical College, Chennai, India - Study conduct; b - Co-Investigators, KI3 (CRO), Chennai, India - Study designing, statistics, and report preparation; and c - Coinvestigators, Apex Laboratories Pvt. Ltd., Chennai, India - Study designing and monitoring. 


\section{REFERENCES}

1. Rehm J, Samokhvalov AV, Shield KD. Global burden of alcoholic liver diseases. J Hepatol 2013;59:160-8.

2. Singhal AK, Bataller R, Ahn J, Kamath PS, Shah VH. ACH clinical guideline: Alcoholic liver disease. Am J Gastroenterol 2018;113:175-94.

3. World Health Organization. Alcohol. Management of Substance Abuse. Available from: http://www.who.int/substance_abuse/facts/alcohol/en/ index.html. [Last accessed on 2018 Sep 21].

4. Spearman CW, Sonderup MW. Health disparities in liver disease in subSaharan Africa. Int Assoc Study Liver 2015;35:2063-71.

5. Frazier TH, Stocker AM, Kershner NA, Marsano LS, McClain CJ. Treatment of alcoholic liver disease. Therap Adv Gastroenterol 2011;4:63-81

6. Sinha SK. Alcoholic liver cirrhosis and herbs. IOSR J Pharm Biol Sci 2015;10:17-31.

7. Kumar EP, Rajan VR, Kumar AD, Parasuraman S, Emerson SF. Hepatoprotective activity of clearliv a polyherbal formulation in Wistar rats. Arch Med Health Sci 2013;1:120-5.

8. Dhiman RK, Chawla YK. Herbal medicines for liver diseases. Dig Dis Sci 2005;50:1807-12.

9. Pingale SS. Hepatosuppression by Ricinus communis against $\mathrm{Ccl} 4$ induced liver toxicity in rats. J Pharm Res 2009;3:39-42.

10. Visen PK, Shukla B, Patnaik GK, Tripathi SC, Kulshreshtha DK,
Srimal RC, et al. Hepatoprotective activity of Ricinus communis Leaves. Pharm Biol 1992;30:241-50.

11. Paithankar VV, Raut KS, Charde RM, Vyas JV. Phyllanthus niruri: A magic herb. Res Pharm 2011;1:1-9.

12. Bhasha S, Shanmugam KR, Doraswamy G, Ravi S, Subbaiah GV, Srinivas K, et al. Hepatoprotective effect of Phyllanthus niruri alkaloid fraction in D-galactosamine induced hepatitis in rats. Int J Pharm Pharm Sci 2016:158-61. Available from: https://www.innovareacademics.in/ journals/index.php/ijpps/article/view/11029/4776. [Last accessed on 2018 Oct 24].

13. Deepa KI, Praboth VS, Snehal SP. Hepatoprotective effect of virgoliv syrup against ccl4 induced hepatic injury in rats. Int J Pharm Pharm Sci 2015:221-6. Available from: https://www.innovareacademics.in/ journals/index.php/ijpps/article/view/5583/2808. [Last accessed on 2018 Oct 24].

14. Suresh DS, Kilambi P, Moinuddin MS. Formulation and evaluation of floating tablet of Eclipta alba extract for hepatic disorders. Int J Pharm Pharm Sci 2015:151-5. Available from: https://www.innovareacademics. in/journals/index.php/ijpps/article/view/4238/2246. [Last accessed on 2018 Oct 24].

15. Ding RB, Tian K, Huang LL, He CW, Jiang Y, Wang YT, et al. Herbal medicines for the prevention of alcoholic liver disease: A review. J Ethnopharmacol 2012;144:457-65. 